\title{
Perceptions of Yemeni physicians about sources of drug information and factors predicting their choices
}

\author{
Mahmoud Al-Areefi ${ }^{1 *}$, Mohamed Izham Mohamed Ibrahim² ${ }^{2}$, Mohamed Azmi Hassali ${ }^{3}$, Abubakr Alfadl ${ }^{4}$ \\ ${ }^{1}$ Faculty of Public Health \& Health Informatics, Umm Al Qura University, Makkah, Saudi Arabia. \\ ${ }^{2}$ College of Pharmacy, Qatar University, Doha, Qatar. \\ ${ }^{3}$ School of Pharmaceutical Sciences, Universiti Sains Malaysia, Gelugor, Malaysia. \\ ${ }^{4}$ Department of Pharmacy Practice, Unaizah College of Pharmacy, Qassim University, Qassim, Saudi Arabia.
}

\section{ARTICLE INFO \\ Received on: 24/05/2021 \\ Accepted on: 13/09/2021 \\ Available Online: 05/12/2021}

\section{Key words:}

Physicians, medical

representatives, sources of

drug information, Yemen.

\begin{abstract}
High-quality information is a necessary prerequisite for an optimum prescribing decision that enhances patient healthcare outcomes. Therefore, the purpose of this study was to identify the main sources of information used by physicians to obtain knowledge about new drugs and to identify the relationship of physicians' characteristics and practice-setting factors with their choices of sources of drug information. To achieve this objective, a crosssectional study was conducted through a questionnaire distributed among physicians in the public and private sectors. Descriptive analysis, factor analysis, $t$-tests, and analysis of variance were carried out to test the differences in the score of "sources of drug information" between categories of physicians' characteristics and practice-setting factors. The study revealed that the majority (96.2\%) of physicians considered medical representatives (MRs) to be their primary source of information about new drugs. Also, MRs seen per week were shown to exert significant differences between groups of physicians for all types of drug information sources, with the exception of noncompany information. In addition, significant differences were seen between groups of physicians sorted by academic affiliation for all types of drug information sources. In conclusion, the majority of physicians use MRs as the main source of information about new drugs. Also, among physicians' characteristics and practice-setting factors, academic affiliation was one of the most influential factors in identifying physicians' preference for sources of information about new drugs.
\end{abstract}

\section{INTRODUCTION}

Prescribing is a challenging process, as it involves clinical decision-making about the drug of choice to best treat a patient with a particular disease. For a scientific-based decision, high-quality and up-to-date information is necessary for an optimum prescribing decision that enhances patient healthcare outcomes. Fortunately, the scientific literature is rich with drug information from a large variety of sources (Layton et al., 2007; Lua et al., 2011; Oshikoya et al., 2011; Othman et al., 2009; Rohra et al., 2007; Tumwikirize et al., 2007). A reliable classification

*Corresponding Author

Mahmoud Al-Areefi, Faculty of Public Health \& Health Informatics, Umm Al Qura University, Makkah, Saudi Arabia.

E-mail:hosinareefi@yahoo.com includes all drug information sources into two main categories: professional and commercial and other sources (Eaton and Parish, 1976; Peay and Peay, 1984, 1990). Although physicians favor noncommercial drug information sources (Layton et al., 2007; Lundborg et al., 1998; Peay and Peay, 1990; Spiller and Wymer, 2001), medical representatives (MRs), among other commercial sources of drug information, are considered to be the most frequent source of information physicians receive (Oshikoya et al., 2011; Rohra et al., 2007).

The pharmaceutical industry devotes huge budgets toward the dissemination of drug information. For example, the National Academy of Medicine revealed that the 12 largest pharmaceutical companies spent more than $\$ 120$ billion on drug promotion in 2016 (National Academies of Sciences, Engineering, and Medicine, 2017). However, this information is mostly provided with the aim of promoting specific drugs to targeted physicians to enhance prescribing with the ultimate 
goal of maximizing returns for the corporation and shareholders rather than promoting innovations or public health (Angel, 2000; Jones et al., 2001; Relman, 2001). This was highlighted in a study conducted during the period from August 2013 to December 2014 revealing that only one-third of the 25 most heavily promoted drugs in the United States can be rated as innovations and only 1 drug was on the WHO's essential medicines list (Greenway and Ross, 2017).

Given the above problem and considering the lack of information due to limited research in developing countries in this area, this study aimed firstly to identify the main sources of information physicians use to obtain knowledge about new drugs and secondly to identify the relationship of physicians' characteristics and practice-setting factors with their choice of sources of drug information. Most previous studies about physicians' sources of drug information did not examine systematic predictors that may explain their preference for a specific source of drug information. This is even more apparent in developing countries where, to the authors' knowledge, comprehensive studies examining predictors of the relationship between demographic characteristics and practice-setting factors of physicians and their preference for a specific type of drug information source are lacking. Therefore, a comprehensive study investigating these relationships in a developing country may be an important contribution to the literature and a necessary step that may help policymakers in those countries develop better informed regulations and policies.

\section{MATERIALS AND METHOD}

\section{Study population and sample size}

This was a descriptive survey involving physicians working at public and private hospitals in Sana'a, the capital city of Yemen. Approximately 1,390 physicians are employed in Sana'a's hospitals. The majority $(1,159)$ of those physicians work in public hospitals, while only 231 work in private facilities. The sample size was calculated to be 385 (Cochran, 1963), but 602 questionnaires were distributed to compensate for responses that were incomplete or not usable.

\section{Data collection}

A questionnaire was developed after thoroughly reviewing the previous literature on sources of drug information (Layton et al., 2007; Strickland-Hodge and Jeqson, 1980). Questions reported in those studies were adapted as necessary and were further modified during the qualitative phase of this study in which 32 physicians were interviewed about their information sources when learning about new drugs registered by the Supreme Board of Drugs and Medical Appliances (Al-Areefi and Hassali, 2013a). Responses were measured on a 5-point Likert scale that ranged from 1 (never) to 5 (always).

A pretest was conducted among 10 physicians in the targeted population. After minor modifications, the questionnaire was piloted among 52 physicians possessing similar population characteristics to test the feasibility, reliability, and validity. The scale was considered to have acceptable reliability with Cronbach's alpha coefficients ranging between 0.638 and 0.840 among the main questionnaire constructs (Nunnally et al., 1967).
Before commencement with data collection, the study protocol was approved by the Ethical Committee of the Ministry of Public Health and Population. Recruitment for the study was based on physicians who agreed to participate. All the questionnaires were completed anonymously, and participants were assured about the confidentiality of the information.

\section{Data analysis}

Statistical Package for the Social Sciences (SPSS) version 16 (SPSS Inc., released 2007) was used for data entry and analysis. Descriptive statistics were used to describe preferences for sources of information. Inferential statistical analyses were used to extract factors and answer the research questions and objectives. Additionally, $t$-tests and analysis of variance (ANOVA) with post-hoc analysis were applied at an a priori significance level of 0.05 .

\section{RESULTS}

\section{Sources of information about new drugs}

To explain their initial sources of information about new drugs, physicians were asked to rate how often they learned about a new drug by rating 12 items of suggested sources of information. The majority $(96.2 \%)$ of physicians considered MRs to be their primary source of information about new drugs, while conferences were rated the least (1.8). The details of the results are presented in Figure 1.

\section{Results of the factor analysis}

Principal component analysis was used to extract factors. The results were obtained through orthogonal rotations with Varimax and all factor loadings greater than 0.40 were retained. Three factors were obtained as shown in Table 1.

Comparing the score of sources of information across groups of physicians sorted by characteristics and practice-setting factors

Independent $t$-tests were carried out to assess the differences in the scores of "company-direct information sources," "company-indirect information sources," and "noncompany information sources" between categories of physicians' characteristics and practice-setting factors with regard to gender, academic affiliation, occupational commitment, private clinic duties, and type of hospital, while ANOVA compared the scores between groups of respondents sorted by position and the number of MRs seen per week. Tukey's Honestly Significant Difference test (HSD) was carried out whenever a significant difference was obtained by ANOVA.

Significant differences were found to exist between groups of physicians sorted by academic affiliation and number of MRs seen per week for all types of drug information sources, with the exception of noncompany information sources, which did not generate a significant difference for the factor "MRs seen per week." Similarly, the "gender" and "occupational commitment" factors were found to have significant differences between groups of physicians for all types of drug information sources, with the exception of company-direct information sources. The results of the $t$-tests and ANOVA did not show significant differences for 


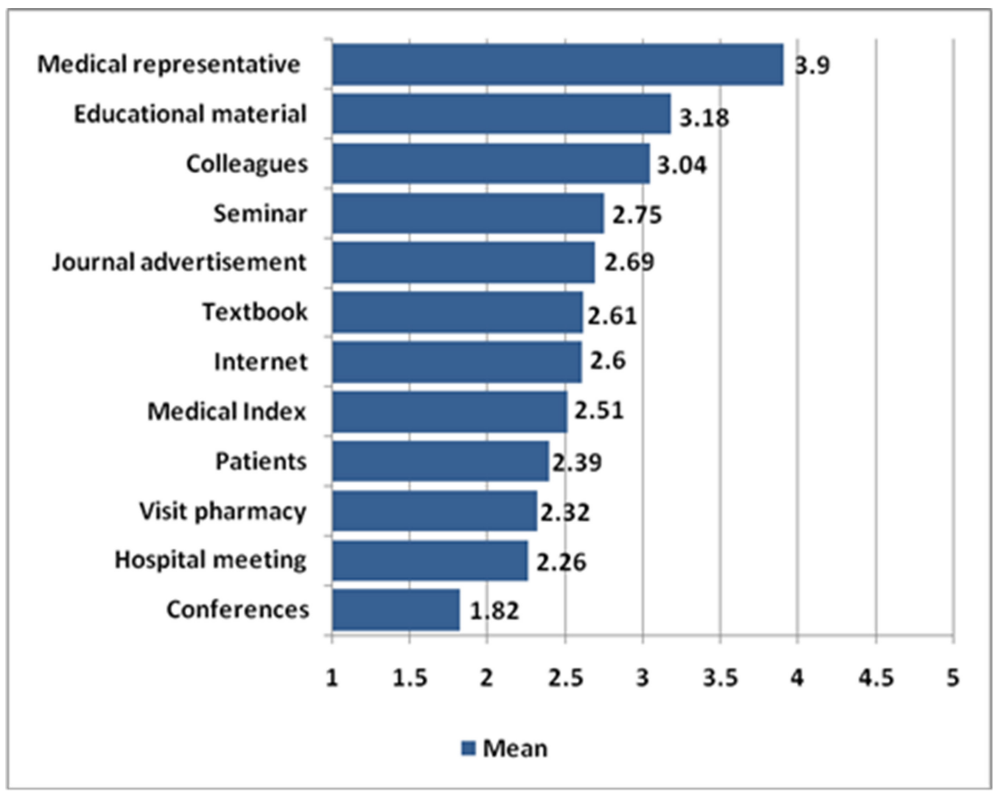

Figure 1. Mean rates of sources of information about new drugs.

Table 1. Results of factor analysis.

\begin{tabular}{llcc}
\hline \multirow{2}{*}{ Factor } & & Component \\
\hline $\begin{array}{c}\text { Company-direct } \\
\text { source }\end{array}$ & Educational materials from drug companies (e.g., studies, brochures, bulletins) & $\mathbf{1}$ & $\mathbf{2}$ \\
& Pharmaceutical companies' MRs & 0.713 & \\
& Attending a seminar or domestic symposia sponsored by the drug industry & 0.670 \\
& Participation in an international conference sponsored by the drug industry & 0.666 \\
\multirow{2}{*}{$\begin{array}{c}\text { Company-indirect } \\
\text { source }\end{array}$} & Visit the pharmacy for the purpose of identifying the new drugs & 0.584 \\
& The Middle East Medical Index, the Monthly Index of Medical Specialties & 0.627 \\
& Patients introduced to a new drug & 0.592 \\
Noncompany & Drug advertisement in medical journal & 0.493 \\
& Colleagues or consultants & 0.740 \\
& Hospital doctors-meetings & 0.688 \\
& Updated medical textbooks & 0.608 \\
& Internet & 0.583 \\
\hline
\end{tabular}

Extraction method: Principal component analysis.

Rotation method: Varimax with Kaiser normalization.

other factors (have clinic, type of hospital, and position). Details of the results of these tests are presented in Tables 2-4.

\section{DISCUSSION}

\section{Sources of information about new drugs}

These results provide evidence that physicians typically learn about new drugs through MRs and educational materials provided by drug companies. This was not a surprise, as marketing new drugs to physicians is an old, well-established strategy adopted by pharmaceutical companies (Cardarelli et al., 2006). The literature shows that MRs represent the most commonly cited source of information about new drugs in both developed and developing countries (Anderson et al., 2009; Datta and Dave, 2017; Ibrahim and Bélanger, 2015; Mikhael, 2015; Negash and Adamu, 2017). Moreover, MRs are perceived as legitimate providers of information in some developing countries (Al-Areefi and Hassali, 2013b). This may be acceptable in countries with poor access to noncompany sources of information, as several studies described MRs as an efficient and convenient source of drug information (Salmasi et al., 2016; Saito et al., 2010). However, a study conducted in Thailand reported that conferences were the most common initial source of information for new drugs, followed by medical journals, but still physicians considered MRs to be an efficient source of information (Layton et al., 2007). 
Table 2. Differences between company-direct information sources among groups of physicians sorted by characteristics and practice-setting factors.

\begin{tabular}{|c|c|c|c|c|c|}
\hline Variable & Factors & Group & $N$ & Mean \pm SD & $p$-value \\
\hline \multirow[t]{18}{*}{ Company-direct source } & \multirow[t]{2}{*}{ Gender $^{a}$} & Male & 334 & $2.92 \pm 0.73$ & \multirow{2}{*}{0.369} \\
\hline & & Female & 115 & $2.85 \pm 0.71$ & \\
\hline & \multirow[t]{2}{*}{ Have clinic ${ }^{\mathrm{a}}$} & Yes & 135 & $2.90 \pm 0.71$ & \multirow{2}{*}{0.910} \\
\hline & & No & 314 & $2.91 \pm 0.73$ & \\
\hline & \multirow{2}{*}{$\begin{array}{l}\text { Occupational } \\
\text { commitment }^{\mathrm{a}}\end{array}$} & Normal day & 340 & $2.91 \pm 0.70$ & \multirow{2}{*}{0.668} \\
\hline & & Overtime & 109 & $2.88 \pm 0.79$ & \\
\hline & \multirow{2}{*}{$\begin{array}{l}\text { Academic } \\
\text { affiliation }^{\text {a }}\end{array}$} & Yes & 68 & $3.14 \pm 0.80$ & \multirow{2}{*}{0.004} \\
\hline & & No & 381 & $2.86 \pm 0.70$ & \\
\hline & \multirow[t]{2}{*}{ Type of hospital ${ }^{\mathrm{a}}$} & Public & 313 & $2.90 \pm 0.69$ & \multirow{2}{*}{0.863} \\
\hline & & Private & 136 & $2.92 \pm 0.79$ & \\
\hline & \multirow[t]{4}{*}{ Position $^{\mathrm{b}}$} & Intern & 25 & $2.63 \pm 0.73$ & \multirow{4}{*}{0.135} \\
\hline & & General Practioners & 115 & $2.90 \pm 0.74$ & \\
\hline & & Residents & 128 & $2.99 \pm 0.68$ & \\
\hline & & Specialist & 181 & $2.89 \pm 0.74$ & \\
\hline & \multirow{4}{*}{$\begin{array}{l}\text { Number of MRs } \\
\text { per week }^{\mathrm{b}}\end{array}$} & Up to 2 & 85 & $2.44 \pm 0.66$ & \multirow{4}{*}{$<0.001$} \\
\hline & & 3 to 5 & 138 & $2.90 \pm 0.64$ & \\
\hline & & 6 to 9 & 115 & $3.10 \pm 0.77$ & \\
\hline & & $\geq 10$ & 111 & $2.09 \pm 0.73$ & \\
\hline
\end{tabular}

Table 3. Differences in score of company-indirect information sources among groups of physicians sorted by characteristics and practice-setting factors.

\begin{tabular}{|c|c|c|c|c|c|}
\hline Variable & Factors & Group & $N$ & Mean \pm SD & $p$ value \\
\hline \multirow[t]{18}{*}{ Company-indirect source } & \multirow[t]{2}{*}{ Gender $^{a}$} & Male & 334 & $2.53 \pm 0.78$ & \multirow{2}{*}{0.009} \\
\hline & & Female & 115 & $2.31 \pm 0.71$ & \\
\hline & \multirow[t]{2}{*}{ Have clinic ${ }^{\mathrm{a}}$} & Yes & 135 & $2.50 \pm 0.84$ & \multirow{2}{*}{0.688} \\
\hline & & No & 314 & $2.46 \pm 0.73$ & \\
\hline & \multirow{2}{*}{$\begin{array}{l}\text { Occupational } \\
\text { commitment }^{\mathrm{a}}\end{array}$} & Normal day & 340 & $2.42 \pm 0.75$ & \multirow{2}{*}{0.012} \\
\hline & & Overtime & 109 & $2.64 \pm 0.79$ & \\
\hline & \multirow{2}{*}{$\begin{array}{l}\text { Academic } \\
\text { affiliation }^{\text {a }}\end{array}$} & Yes & 68 & $2.71 \pm 0.92$ & \multirow{2}{*}{0.005} \\
\hline & & No & 381 & $2.43 \pm 0.73$ & \\
\hline & \multirow[t]{2}{*}{ Type of hospital ${ }^{\mathrm{a}}$} & Public & 313 & $2.46 \pm 0.77$ & \multirow{2}{*}{0.503} \\
\hline & & Private & 136 & $2.51 \pm 0.77$ & \\
\hline & \multirow[t]{4}{*}{ Position $^{\mathrm{b}}$} & Intern & 25 & $2.32 \pm 0.72$ & \multirow{4}{*}{0.581} \\
\hline & & GPs & 115 & $2.54 \pm 0.77$ & \\
\hline & & Residents & 128 & $2.47 \pm 0.70$ & \\
\hline & & Specialist & 181 & $2.46 \pm 0.81$ & \\
\hline & \multirow{4}{*}{$\begin{array}{l}\text { Number of MRs } \\
\text { per week }^{\mathrm{b}}\end{array}$} & up to 2 & 85 & $2.27 \pm 0.68$ & \multirow{4}{*}{0.002} \\
\hline & & 3 to 5 & 138 & $2.44 \pm 0.72$ & \\
\hline & & 6 to 9 & 115 & $2.45 \pm 0.77$ & \\
\hline & & $\geq 10$ & 111 & $2.69 \pm 0.82$ & \\
\hline
\end{tabular}

${ }^{a}$ Independent $t$-test.

${ }^{\mathrm{b}}$ One-way ANOVA test was conducted at $\alpha=0.05$. 
Table 4. Differences in score of noncompany information sources among groups of physicians sorted by characteristics and practice-setting factors.

\begin{tabular}{|c|c|c|c|c|c|}
\hline Variable & Factors & Group & $N$ & Mean \pm SD & $p$ value \\
\hline \multirow[t]{18}{*}{ Noncompany source } & \multirow[t]{2}{*}{ Gender $^{\mathrm{a}}$} & Male & 334 & $2.68 \pm 0.88$ & \multirow{2}{*}{0.005} \\
\hline & & Female & 115 & $2.45 \pm 0.73$ & \\
\hline & \multirow[t]{2}{*}{ Have clinic ${ }^{\mathrm{a}}$} & Yes & 135 & $2.57 \pm 0.89$ & \multirow{2}{*}{0.347} \\
\hline & & No & 314 & $2.65 \pm 0.83$ & \\
\hline & \multirow{2}{*}{$\begin{array}{l}\text { Occupational } \\
\text { commitment }^{\mathrm{a}}\end{array}$} & Normal day & 340 & $2.57 \pm 0.81$ & \multirow{2}{*}{0.028} \\
\hline & & Overtime & 109 & $2.79 \pm 0.93$ & \\
\hline & \multirow{2}{*}{$\begin{array}{l}\text { Academic } \\
\text { affiliation }^{\text {a }}\end{array}$} & Yes & 68 & $2.87 \pm 0.94$ & \multirow{2}{*}{0.008} \\
\hline & & No & 381 & $2.58 \pm 0.82$ & \\
\hline & \multirow[t]{2}{*}{ Type of hospital ${ }^{\mathrm{a}}$} & Public & 313 & $2.59 \pm 0.86$ & \multirow{2}{*}{0.274} \\
\hline & & Private & 136 & $2.69 \pm 0.82$ & \\
\hline & \multirow[t]{4}{*}{ Position $^{b}$} & Intern & 25 & $2.88 \pm 0.73$ & \multirow{4}{*}{0.448} \\
\hline & & GPs & 115 & $2.59 \pm 0.89$ & \\
\hline & & Board (resident) & 128 & $2.60 \pm 0.71$ & \\
\hline & & specialist & 181 & $2.63 \pm 0.92$ & \\
\hline & \multirow{4}{*}{$\begin{array}{c}\text { Number of MRs } \\
\text { per week }^{\mathrm{b}}\end{array}$} & up to 2 & 85 & $2.57 \pm 0.81$ & \multirow{4}{*}{0.052} \\
\hline & & 3 to 5 & 138 & $2.49 \pm 0.77$ & \\
\hline & & 6 to 9 & 115 & $2.69 \pm 0.83$ & \\
\hline & & $\geq 10$ & 111 & $2.76 \pm 0.96$ & \\
\hline
\end{tabular}

Generally, the findings presented in this study support previous studies reporting that information from commercial sources was received more often than was information from noncommercial sources (Eaton and Parish, 1976; Lundborg et al., 1998; Skoglund et al., 2011). In some countries, commercial sources of drug information represented the only source on which physicians depend for updating their knowledge about new or even existing drugs (Ganashree et al., 2016; Phoolgen et al., 2012; Sharmin et al., 2017). This may be worrying as a previous review reported that whenever an association was detected, exposure to commercial sources of drug information was associated with lower prescribing quality, an increase in prescribing frequency, or an increase in prescribing costs (Spurling et al., 2010). Other studies claimed that these commercial sources of information could be incomplete and with questionable credibility, as well as being most effective as sales rather than informational materials (Hailu et al., 2019; Parli et al., 2017). However, considering the time constraints for most of them, as well as the rapid development of innovations in medicine accompanied by a large number of information sources, has posed problems for physicians to keep updated with the latest information about new drugs. Consequently, the need for information sources that are objective, organized, and concise may have led physicians toward higher reliance on commercial sources (Tumwikirize et al., 2007; Vyas and Bhave, 2018).

\section{Relationships between physicians' characteristics and practice- setting factors and physicians' choices regarding sources of drug information}

Factor analysis revealed that physicians perceive sources of information about new drugs such as company-direct sources, company-indirect sources, and noncompany sources. These results provide evidence of consistent patterns of physicians having been exposed to sources of information about new drugs.

The study showed that, with regard to company-direct sources of information, those physicians who held an academic affiliation had more exposure than those who did not and they were more likely to learn about new drugs directly from company sources. This finding may reflect the companies' attempts to target opinion leaders and professionals, as these influential doctors are often engaged by the industry to offer advice on marketing in an effort to boost the sales of new medicines (Jureidini and McHenry, 2009; Moynihan, 2008). Also, it was found that physicians who received more than two visits per week from MRs had more exposure to company-direct information sources than did those who received two visits or fewer. Several studies support this observation (Afi et al., 2014; Anderson et al., 2009; Ibrahim and Bélanger, 2015; Shafi, 2014). However, it contrasts the findings of Layton et al. (2007), who ranked MRs the lowest after international journals and conferences. No consistent pattern emerged in the study of other physicians' characteristics and practice-setting factors in relation to exposure to company-direct information sources about new drugs. This contradicts a study conducted in Japan that reported a significant difference between male and female physicians with regard to the consumption of company-direct information sources (Saito et al., 2010).

The study also revealed that, similar to company-direct information sources, physicians with an academic affiliation had more exposure to company-indirect sources of information than those who did not have such an affiliation. Perhaps this is because MRs are typically selective in how they distribute 
promotions such as journals and medical indices. However, the previous literature reported that holding an academic appointment generally influenced physicians' use of drug information sources (Gaither et al., 1994). In addition to academic affiliation, the study also showed that male respondents, those working overtime, or those who received more than nine visits per week by MRs had greater exposure to company-indirect information sources. This finding may reflect the cultural aspect in Yemen that prevents female physicians from working overtime at hospitals. On the other hand, no difference in physicians' use of company-indirect sources of information was observed depending on "have clinic," "type of hospital," and "position." However, several other studies reported findings contradicting this current observation (Alssageer and Kowalski, 2012; Hodges, 1995).

Regarding noncompany information sources, this study revealed that respondents who have an academic affiliation are male and who work overtime typically learn about new drugs via noncompany information sources such as colleagues or consultants, hospital meetings, up-to-date medical textbooks, and the Internet. This finding supports those of Peay and Peay (1990), who suggested that doctors in the hospital setting exhibit a preference for professional sources of information, while doctors in the community setting (private) showed a preference for commercial sources.

\section{CONCLUSION}

Sources of information about new drugs that were most frequently cited by Yemeni physicians included MRs, educational materials, and colleagues. Also, among physicians' characteristics and practice-setting factors, academic affiliation was found to be one of the most influential factors in identifying a physician's preference for sources of information about new drugs. These findings may be helpful for health policymakers in designing a more efficient policy addressing physicians' need for reliable, scientific information about new drugs.

\section{CONFLICT OF INTEREST}

No conflicts of interest have been declared by the authors.

\section{FUNDING}

This research received no specific grant from any funding agency in the public, commercial, or not-for-profit sectors.

\section{CONSENT TO PARTICIPATE}

Recruitment for the study was based on physicians who agreed to participate. All physicians gave verbal consent before being included in the study.

\section{ETHICAL APPROVAL}

The study protocol was approved by the Ethical Committee of the Ministry of Public Health and Population (reference number is not available).

\section{AUTHORS' CONTRIBUTIONS}

MAA participated in the design of the study and carried out the statistical analysis and participated in drafting the manuscript. MMI participated in the design of the study and critically reviewed the draft of the manuscript. MAH participated in the design of the study and critically reviewed the draft of the manuscript. AAA drafted the manuscript and participated in critically reviewing it. All authors read and approved the final manuscript.

\section{REFERENCES}

Afi Kayi E, Atinga RA, Ansa GA. Informational sources on pharmaceutical medicines and factors affecting medication prescriptions: perspectives from Ghanaian physicians. J Med Mark, 2014; 14(4):176-81.

Al-Areefi MA, Hassali MA. Physicians' perceptions of medical representative visits in Yemen: a qualitative study. BMC Health Serv Res, 2013a; 13(1):1-8

Al-Areefi MA, Hassali MA. The role of pharmaceutical marketing and other factors in prescribing decisions: the Yemeni experience. Res Social Adm Pharm, 2013b; 9(6):981-8.

Alssageer MA, Kowalski SR. A survey of pharmaceutical company representative interactions with doctors in Libya. Libyan J Med 2012; 7(1):1-19.

Anderson BL, Silverman GK, Loewenstein GF, Zinberg S, Schulkin J. Factors associated with physicians' reliance on pharmaceutical sales representatives. Acad Med, 2009; 84(8):994-1002.

Angel M. The pharmaceutical industry-to whom is it accountable? NEJM, 2000; 342:1902-4.

Cardarelli R, Licciardone JC, Taylor LG. A cross-sectional evidence-based review of pharmaceutical promotional marketing brochures and their underlying studies: is what they tell us important and true? BMC Fam Pract, 2006; 7(1):1-6.

Cochran W. Sampling techniques. John Wiley \& Sons, Ltd., New York, NY, 1963.

Datta A, Dave D. Effects of physician-directed pharmaceutical promotion on prescription behaviors: longitudinal evidence. Health Econ, 2017; 26(4):450-68.

Eaton G, Parish P. Sources of drug information used by general practitioners. J R Coll Gen Pract, 1976; 26(1):58-64.

Gaither CA, Bagozzi RP, Kirking DM, Ascione FJ. Factors related to physicians' attitudes and beliefs toward drug information sources. Drug Inf J, 1994; 28(3):817-27.

Ganashree P, Bhuvana K, Sarala N. Critical review of drug promotional literature using the World Health Organization guidelines. J Res Pharm Pract, 2016; 5(3):162.

Greenway T, Ross J. US drug marketing: how does promotion correspond with health value? Br Med J, 2017; 357:1855.

Hailu HG, Gobezie MY, Yesuf TA, Workneh BD. Critical evaluation of the validity of drug promotion materials in Ethiopia. Drug Healthc Patient Saf, 2019; 11:47.

Hodges B. Interactions with the pharmaceutical industry: experiences and attitudes of psychiatry residents, interns and clerks. Can Med Assoc J, 1995; 153(5):553.

Ibrahim IAY, Bélanger $\mathrm{CH}$. Pharmaceutical representatives and prescription decisions by physicians in Saudi Arabia. J Mark Manage, 2015; 3:69-79.

Jones MI, Greenfield SM, Bradley CP. Prescribing new drugs: qualitative study of influences on consultants and general practitioners. $\mathrm{Br}$ Med J, 2001; 323(7309):378-81.

Jureidini JN, McHenry LB. Key opinion leaders and paediatric antidepressant overprescribing. Psychother Psychosom, 2009; 78(4):197-201.

Layton MR, Sritanyarat W, Chadbunchachai S, Wertheimer AI Sources of information for new drugs among physicians in Thailand. World J Pharm Res, 2007; 29(6):619-27.

Lua HL, Sklar G, Ko Y. Identification and physicians' views of their commonly-used drug information sources in Singapore. Int J Clin Pharm, 2011; 33(5):772-8.

Lundborg CS, Hensjö LO, Gustafsson LL. Drug information sources: reported preferences by general practitioners. Drug Inf J, 1998; 32(3):777-85. 
Mikhael EM. Evaluating the reliability and accuracy the promotional brochures for the genetic pharmaceutical companiesin Iraq using WHO guidelines. J Pharma Bioall Sci, 2015; 7(1):65-8.

Moynihan R. Key opinion leaders: independent experts or drug representatives in disguise? Br Med J, 2008; 336(7658):1402-3.

National Academies of Sciences, Engineering, and Medicine. Making medicines affordable: a national imperative. The National Academies Press, Washington, DC, 2017.

Negash M, Adamu A. The impact of pharmaceutical promotion strategies on prescribing behavior of physicians a developing country experience: case of Addis Ababa, Ethiopia. Pac Busi Rev Int, 2017; 9(8): $9-18$.

Nunnally JC, Bernstein IH, Berge JMF. Psychometric theory. McGraw-Hill, New York, NY, 1967.

Oshikoya KA, Oreagba I, Adeyemi O. Sources of drug information and their influence on the prescribing behaviour of doctors in a teaching hospital in Ibadan, Nigeria. Pan Afr Med J, 2011; 9(1):13.

Othman N, Vitry A, Roughead EE. Quality of pharmaceutical advertisements in medical journals: a systematic review. PLoS One, 2009; 4(7):e6350; doi:10.1371/journal.pone.0006350.

Parli K, Reema R, Devang R, Supriya M. Evaluation of promotional drug literature provided by medical representative at a tertiary care hospital. Int J Pharm Sci Res, 2017; 8(4):1744.

Peay MY, Peay ER. Differences among practitioners in patterns of preference for information sources in the adoption of new drugs. Soc Sci Med, 1984; 18(12):1019-25.

Peay MY, Peay ER. Patterns of preference for information sources in the adoption of new drugs by specialists. Soc Sci Med, 1990; 31(4):467-76.

Phoolgen S, Kumar SA, Kumar RJ. Evaluation of the rationality of psychotropic drug promotional literatures in Nepal. J Drug Discov Ther, 2012; 2(6):6-8.

Relman AS. Separating continuing medical education from pharmaceutical marketing. J Am Med Assoc, 2001; 285(15):2009-12.

Rohra DK, Sukkurwala A, Palanpurwala A, Gangwani R. Prescription of new drugs by general practitioners in Pakistan: an exploration into information sources, prescription influences and general attitudes. Pak J Med Res, 2007; 46(1):5-10.

Saito S, Mukohara K, Bito S. Japanese practicing physicians' relationships with pharmaceutical representatives: a national survey. PLoS One, 2010; 5(8):e12193.

Salmasi S, Ming LC, Khan TM. Interaction and medical inducement between pharmaceutical representatives and physicians: a meta-synthesis. J Pharm Policy Pract, 2016; (1)9.

Shafi V. Prescribing behaviour of physicians in Karachi, Pakistan. World J Pharm Res, 2014; (3)3:3528-36.
Sharmin R, Sharmin ZR, Mosaddek ASM, Islam MZ, Rahman MF, Parvin R, Sultana SP, Haque M. Medicine promotional literature as a source of updated information in Bangladesh: do those advertising literature promote continued medical education or deceptive advertising? Acta Medica Int, 2017; 4(2):20.

Skoglund I, Bjorkelund C, Mehlig K, Gunnarsson R, Moller M. GPs' opinions of public and industrial information regarding drugs: a crosssectional study. BMC Health Serv Res, 2011; 11(1):1-8.

Spiller LD, Wymer WW. Physicians' perceptions and uses of commercial drug information sources. Health Mark Q, 2001; 19(1):91-106.

Spurling GK, Mansfield PR, Montgomery BD, Lexchin J, Doust J, Othman N, Vitry AI. Information from pharmaceutical companies and the quality, quantity, and cost of physicians' prescribing: a systematic review. PLoS Med, 2010; 7(10): e1000352.

Strickland-Hodge B, Jeqson MH. Usage of information sources by general practitioners1. J Royal Soc Med, 1980; 73(12):857-62.

Tumwikirize WA, Ogwal-Okeng JW, Vernby Å, Anokbonggo WW, Gustafsson LL, Lundborg CS. Access to up-to-date drug information in developing countries continues to pose problems: the case of Uganda. Pharmacoepidemiol Drug Saf, 2007; 16(10):1177-9.

Vyas PP, Bhave AL. Evaluation of scientific and ethical status of drug promotional literatures (DPLs) for ethical medicinal drug promotion. Int J Cur Res Rev, 2018; 10(5):30.

How to cite this article:

Al-Areefi M, Mohamed Ibrahim MI, Hassali MA, Alfadl A. Perceptions of Yemeni physicians about sources of drug information and factors predicting their choices. J Appl Pharm Sci, 2021; 11(12):114-120. 